\title{
Effects of Women's Autonomy and Male Involvement on Reproductive and Child Health (RCH) Service Utilization in Uttar Pradesh
}

\author{
Damodar Sahu1, Tapati Dutta ${ }^{2}$, Sanjay Kumar1, Nihar Ranjan Mishra ${ }^{3}$, Sharmila Neogi ${ }^{3}$, \\ Subrato Mondal ${ }^{3}$, Anju Dadhwal-Singh ${ }^{2}$, Marta Levitt-Dayal² \\ ${ }^{1}$ National Institute for Medical Statistics, ICMR Campus, New Delhi, India \\ ${ }^{2} \mathrm{MCH}-\mathrm{STAR}$ Initiative, New Delhi, India \\ ${ }^{3}$ Population Foundation of India, New Delhi, India \\ Email: info@mchstar.org
}

How to cite this paper: Sahu, D., Dutta, T., Kumar, S., Mishra, N.R., Neogi, S., Mondal, S., Dadhwal-Singh, A. and Levitt-Dayal, M. (2016) Effects of Women's Autonomy and Male Involvement on Reproductive and Child Health $(\mathrm{RCH})$ Service Utilization in Uttar Pradesh. Open Journal of Preventive Medicine, 6, 260-271.

http://dx.doi.org/10.4236/ojpm.2016.611024

Received: September 23, 2016

Accepted: November 19, 2016

Published: November 23, 2016

Copyright $\odot 2016$ by authors and Scientific Research Publishing Inc. This work is licensed under the Creative Commons Attribution International License (CC BY 4.0).

http://creativecommons.org/licenses/by/4.0/

\section{Abstract}

Introduction: Effective utilization of reproductive and child health ( $\mathrm{RCH})$ services is important to reduce morbidity and mortality among mothers as well as children under-five. After International Conference on Population and Development (ICPD), 1994 India has increasingly integrated male participation in women's reproductive health to improve the women's health care during pregnancy and child birth. This study examined effect of women's autonomy and male involvement on $\mathrm{RCH}$ services utilization in Uttar Pradesh State of India. Methodology: State level data of Uttar Pradesh from National Family Health Survey (NFHS-3), India for currently married women and men aged 15 - 49 years was considered. The study was restricted to couples whose youngest child was born during the three years preceding the survey $(\mathrm{N}=2685)$. Pearson chi-square test was used to determine the association of background characteristics with woman's autonomy and male involvement in RCH utilization. Logistic regression was used to understand the effects of male involvement and women's autonomy, using both computed indices after controlling for socio-economic and background characteristics of women and their husbands. Subsequently, the exercise was extended using individual component of both the indices. All findings were reported for $95 \% \mathrm{CI}$ and $\mathrm{p}<0.05$. Results: Findings show that except religion, other socio-economic and demographic variables such as age of women, place of residence, number of living children, caste/tribe, women's work status, education, wealth index, household structure and exposure to mass media, husband's age, education, and occupation were statistically significant and associated with women's autonomy and male involvement. Multivariate analysis indicated women's autonomous decision making and support from their husbands (male involvement) 
significantly influenced their utilization of RCH services after controlling for all socio-economic and demographic variables. Conclusion: To improve $\mathrm{RCH}$ service utilization and overall health status of women and children male involvement and women's autonomous decision-making should be addressed in all future RCH programs in the State.

\section{Keywords}

Women's Autonomy, Male Involvement, RCH, Uttar Pradesh

\section{Introduction}

The International Conference on Population and Development (ICPD) Cairo Plan of Action (PoA) emphasized the need to "promote gender equality in all spheres of life and to encourage and enable men to take responsibility for their sexual and reproductive behavior and their social and family role" (Sen 1994) [1]. Many countries, including India, have increasingly shifted their focus in reproductive and child health programs towards greater male participation in the reproductive health of women, especially to improve the women's health care during pregnancy and child birth. (Cohen 1994) [2]. In the ICPD+10 progress report, UNFPA states that "a major remaining challenge is the promotion of greater male responsibility in family and reproductive decision-making" and suggests that full implementation of ICPD PoA is essential for empowerment and equality of women, and that women's reproductive health is the key to their empowerment (UNFPA, 2004) [3].

Despite various national and international initiatives to improve maternal health, more than half a million women from developing countries die each year as a result of complications related to pregnancy and child birth (Ronsmans and Graham, 2006; World Health Organization 2005) [4] [5]. With approximately 247,000 maternal deaths per year, sub-Saharan Africa shares nearly half of the toll despite accounting for less than 12 percent of the world population (World Health Organization, 2004) [6]. There is wide recognition that one major factor contributing to high maternal mortality is the low use of maternal health services for delivery; yet the proportion of deliveries assisted by health professionals in sub-Saharan Africa has remained very low and progressed only marginally from 42 percent in 1990 to 46 percent in 2004 (United Nations, 2006) [7]. In seeking to explain these low levels of health care utilization in developing countries, most studies have focused on provision and geographic accessibility of services, and relatively very few have looked at how factors such as women's autonomy and male involvement influence use of services (Cham et al., 2005; Furuta and Salway, 2006; Dutta et al. 2010) [8] [9] [10]. Woman's autonomy is generally defined as the ability to make and execute decisions regarding personal matters of importance on the basis of the woman's power over others, access to information, control over material resources, and freedom from violence by her husband or other men (Caldwell and Caldwell, 1993; Dyson and Moore, 1983; Jejeebhoy and Sathar, 2001) [11] [12] [13]. 
Number of studies have examined the effect of women's autonomy and their reproductive health outcomes in the context of the developing world (Ghuman, 2003) [14]. These studies have shown that lower family size and desired fertility are observed among women with higher levels of autonomy (Mason, 1987) [15]; higher rates of contraceptive prevalence were recorded among women with greater interpersonal control (Miles-Doan and Bisharat, 1990; Moursund and Kravdal, 2003) [16] [17]; and lower rates of child mortality were observed among women with more decision-making power (Dharmalingam and Morgan, 1996) [18]. Comparatively much less research has focused on the relationship between women's status and male involvement on the Reproductive and Child Health (RCH) service utilization (Sunil et al. 2006) [19].

In India, since 2000, three important documents, the National Population Policy (2000), the Uttar Pradesh Population Policy (2000) [20] and the 10th Five-Year Plan (2002-2007) [21], have mentioned the importance of male involvement in Planned Parenthood (M.E. Khan and P. Panda, 2004) [22]. Uttar Pradesh is ranked 18th among twenty States in India according to the Human Development Index (HDI) constituted from demographic, health care, basic infrastructure, education, unemployment and poverty, and social deprivation indicators (CSD, 2007) [23]. In Uttar Pradesh, a woman's engagement in household decision-making, including for her own health care, is low. Her mobility is often determined by male members in the family, mostly her husband (Indian Institute of Population Sciences and Macro-International, 2007) [24]. Therefore, to increase gender equity in the society, women require greater autonomy.

The State Innovations in Family Planning Services Project Agency (SIFPSA) in Uttar Pradesh, with support from USAID's Maternal and Child Health Sustainable Technical Assistance and Research (MCH-STAR) Project, organized an Advocacy Workshop on Gender and RCH. In preparation for this workshop, MCH-STAR and its partners explored the effects of gender on $\mathrm{RCH}$ service utilization and outcomes through a series of multivariate analyses of the Uttar Pradesh DHS 2005-06 data sets. This paper presents the findings of an analysis completed by the Population Foundation of India (PFI) and MCH-STAR on the effects of male involvement and women's autonomous decision-making on $\mathrm{RCH}$ service utilization in Uttar Pradesh.

\section{Objective}

The main objective of this paper is to examine the effects of women's autonomous decision-making power and male involvement on utilization of various $\mathrm{RCH}$ services among couples whose youngest child is aged 0 - 35 months in Uttar Pradesh.

\section{Methodology}

Keeping in view the above objective, the present paper used data from the India DHS, known as the National Family Health Survey-3 (NFHS-3), conducted in 2005-2006 [25] for the State of Uttar Pradesh for currently married women and men aged 15 - 49. Information on $\mathrm{RCH}$ service utilization was collected for women who gave birth within three years preceding the survey and for men whose youngest child was under 3 years 
of age. The present paper is restricted to those couples whose youngest child was born during the three years preceding the survey $(\mathrm{N}=2685)$.

In families, there are certain activities on which decisions are made by the husband alone or made by the wife alone or made jointly by spouses. In addition, sometimes decisions may be made with other influential persons in the household. A set of decision-making questions were asked in NFHS-3 survey to elicit information on who takes household decisions-the woman alone, jointly with husband, the husband alone, or with another person of the household. A composite index of woman's autonomous decision-making was developed assigning weight to each individual option i.e., weight 3 is assigned if the final decision is by the woman alone; 2 if the final decision is by the woman jointly with her husband; and 1 if final decision is made by the husband alone or by the husband with another person of the household.

The variables considered for constructing a Women's Autonomy Index were- "final say on making large household purchases", "final say on making household purchases for daily needs", "final say on visits to family or relatives" and "final say on deciding what to do with money husband earns". The composite score computed by aggregating the weights for each of the variable and women's autonomy index has been defined as low autonomy if the combined score is between 4 and 6, medium autonomy if the score is either 7 or 8, and high autonomy if the score is between 9 and 12 .

Similarly, a Male Involvement Index was developed considering a set of questions from the NFHS-3 questionnaire, where the husband was involved in or had received information about maternal health services. For the purpose of this analysis, male involvement was defined as:

1) Husband and wife jointly make decisions on women's own health care, or

2) Husband present at the time of antenatal care (ANC) visit, or

3) Husband told by heath provider or heath worker about the signs of pregnancy complication (vaginal bleeding or convulsion or prolonged labour), or

4) Husband told by heath provider or heath worker about importance of delivery in a health facility.

If the response to all four questions was " $n o$ ", the index has been classified as "No male involvement"; if the response to any one or two questions was "yes", the index has been classified as "Partial male involvement"; if the response to any three or more questions is "yes", it is termed as "High male involvement".

The Pearson chi-square test was used to determine the association of background characteristics with woman's autonomy and male involvement behaviour. Multivariate logistic regression model was used to understand the effect of male involvement and woman's autonomy, using both computed indices after controlling for socio-economic and demographic background characteristics of women and their husbands. Subsequently, the exercise was extended using individual component of both the indices.

A number of socio-economic and demographic characteristics such as age of women, place of residence, number of living children, religion, caste/tribe, women's work status, education, wealth index, household structure and exposure to mass media were included under the present analysis. RCH programme service variables such as antenatal 
care, which includes 3 or more ANC visits, at least two Tetanus-toxoid (TT) injections, 90 or more Iron/Folic Acid (IFA) tablets received, and full ANC; delivery at a health facility and delivery assisted by health professional; post-natal care; initiation of breastfeeding within one hour; Bacillus Calmette-Guérin (BCG), diphtheria, tetanus and pertussis (DPT3), Polio3, Measles vaccines and full vaccination; nutritional status (stunting, wasting and underweight); and childhood morbidities (fever, diarrhoea, acute respiratory infections-ARI) were included under the purview of the analysis.

\section{Key Findings}

It is evident from Table 1 that women's autonomy and male involvement is associated with the utilization of various RCH services. With high level of women's autonomy and high level of male involvement antennal care and institutional delivery is likely to be higher (Figures 1-4). The findings also show that except religion, all socio-economic and demographic variables are found to be associated with women's autonomy and male involvement. Women's autonomy varies by background characteristics such as age of women, place of residence, number of living children, caste/tribe, women's work status, education, wealth index, household structure and exposure to mass media, husband's age, education, and occupation. All individual components of male involvement and women's autonomy index are also found to be associated with all above-mentioned socio-economic and demographic variables.

\subsection{Women's Autonomy}

Table 2 indicates that after adjusting for other covariates such as woman's age, place of

Table 1. Use of RCH services by women's autonomy and male involvement.

\begin{tabular}{|c|c|c|c|c|c|c|}
\hline \multirow{2}{*}{ RCH Services } & \multicolumn{3}{|c|}{ Women's Autonomy } & \multicolumn{3}{|c|}{ Male Involvement } \\
\hline & Low & Medium & High & No & Partial & High \\
\hline $\begin{array}{l}\text { Percentage of Currently married women } \\
\text { who received at least } 3 \text { Antenatal Check up }\end{array}$ & 25.7 & 25.1 & 33.4 & 16.2 & 29.1 & 45.6 \\
\hline $\begin{array}{l}\text { Percentage of Currently married women } \\
\text { who delivered in a Health Facility }\end{array}$ & 25.7 & 25.1 & 33.4 & 13.2 & 22.6 & 41.6 \\
\hline $\begin{array}{l}\text { Percentage of Currently married women } \\
\text { whose deliveries were attended by skilled } \\
\text { health personnel }\end{array}$ & 31.1 & 26.7 & 25.6 & 16.5 & 30.7 & 50.2 \\
\hline $\begin{array}{l}\text { Percentage of Currently married women } \\
\text { currently using any family planning method }\end{array}$ & 44.1 & 43.1 & 44.3 & 38.8 & 45.3 & 51.7 \\
\hline $\begin{array}{l}\text { Percentage of women who utilized ICDS } \\
\text { services during pregnancy }\end{array}$ & 3.8 & 3.8 & 3.2 & 1.4 & 4.3 & 2.9 \\
\hline $\begin{array}{l}\text { Percentage of children under age three } \\
\text { years stunted (height-for-age) }\end{array}$ & 52.4 & 55.7 & 55.3 & 58.1 & 53.3 & 43.7 \\
\hline $\begin{array}{l}\text { Percentage of children under age three } \\
\text { years wasted (weight-for-age) }\end{array}$ & 43.1 & 45.3 & 38.8 & 48.4 & 42.3 & 33.6 \\
\hline
\end{tabular}

Source: Computed from NFHS III data file. 


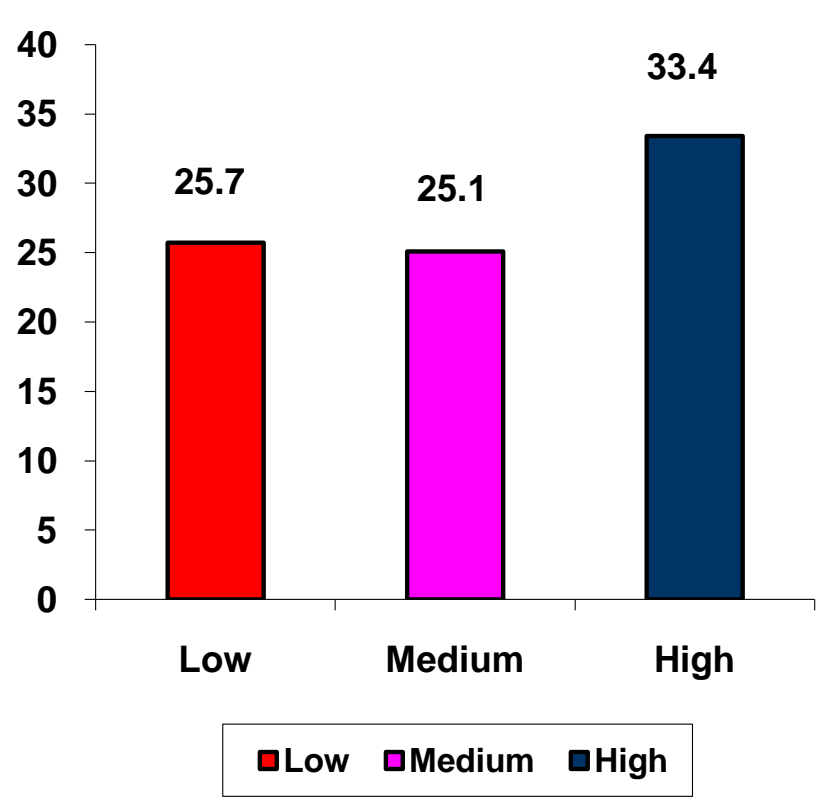

Figure 1. Percentage of currently married women who received at least 3 antenatal check-up by woman autonomy, Uttar pradesh, 2005-06. * $\mathrm{p}<0.05$.

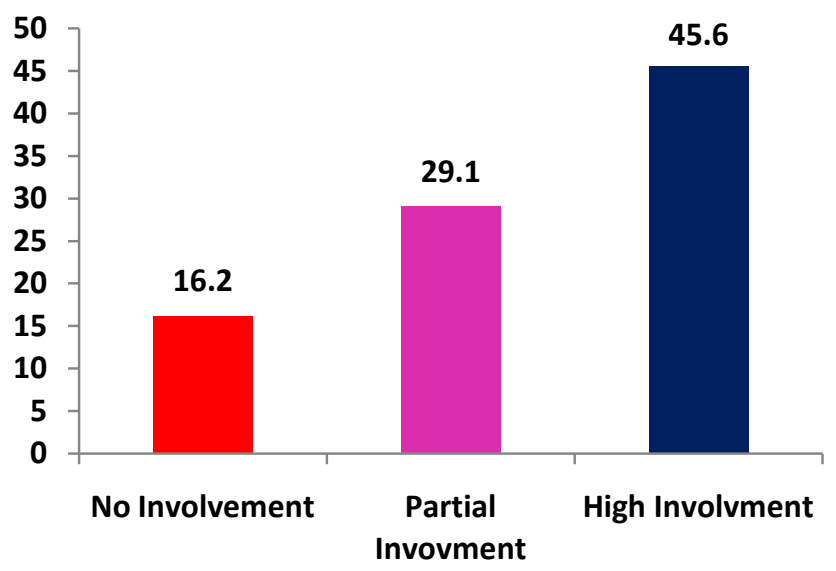

Figure 2. Percentage of currently married women who received at least 3 antenatal check-up by male involvement, Uttar Pradesh, 2005-06.

residence, having currently living children, caste/tribe, women's education status, women's standard of living (wealth index), type of family, exposure to mass media, husband's age, education, and occupation, high autonomy of women was found to be positively associated with full antenatal care $(\mathrm{OR}=2.48, \mathrm{p}<0.05)$. Women who make their own decisions are two and a half times more likely to have received full antenatal care than women with low autonomy. Women's autonomy is significantly associated with child morbidities i.e., fever or any morbidity. Women's autonomy in Uttar Pradesh was not significantly associated with other $\mathrm{RCH}$ service variables as shown in Table 2. 


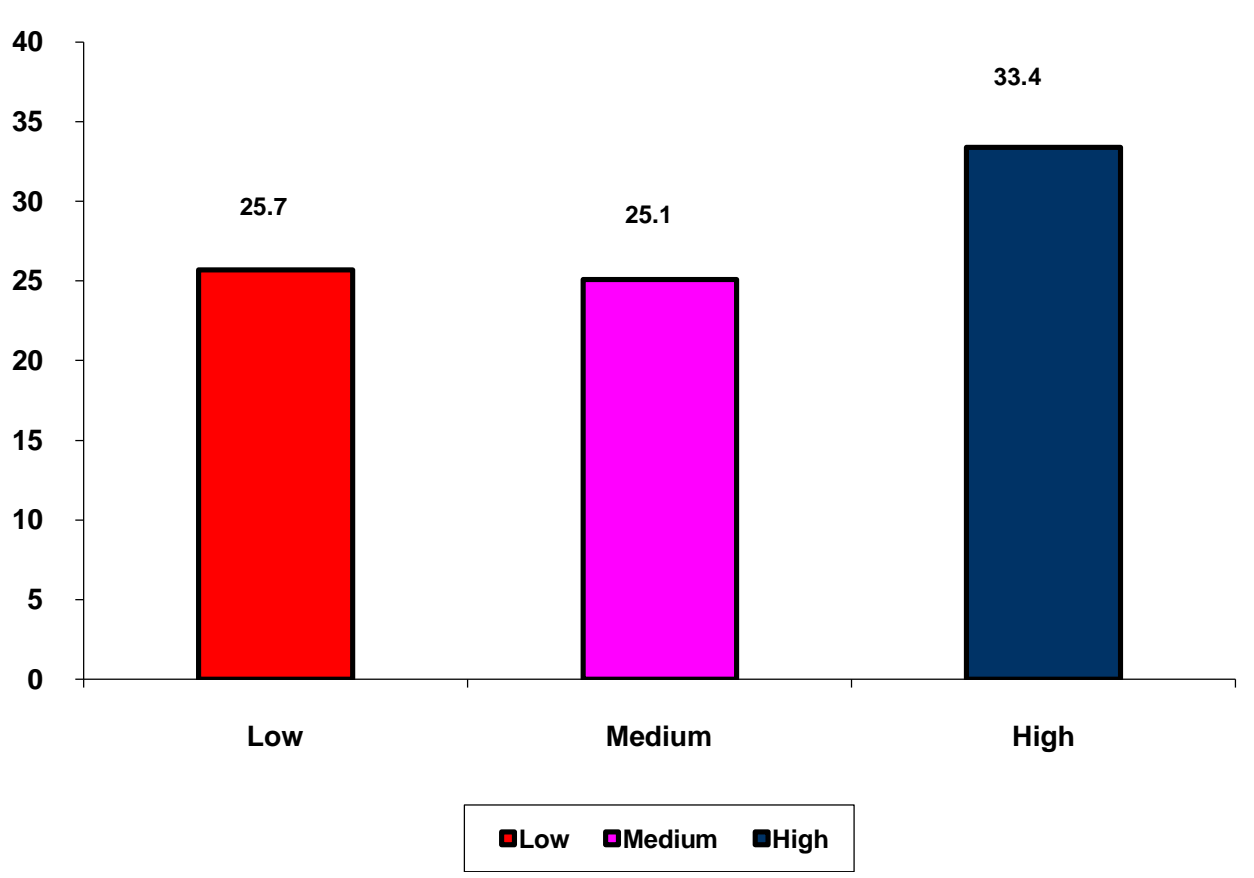

Figure 3. Percentage of currently married women who delivered in a health facility by woman autonomy, uttar pradesh, 2005-06. ${ }^{\star} \mathrm{p}<0.10$.

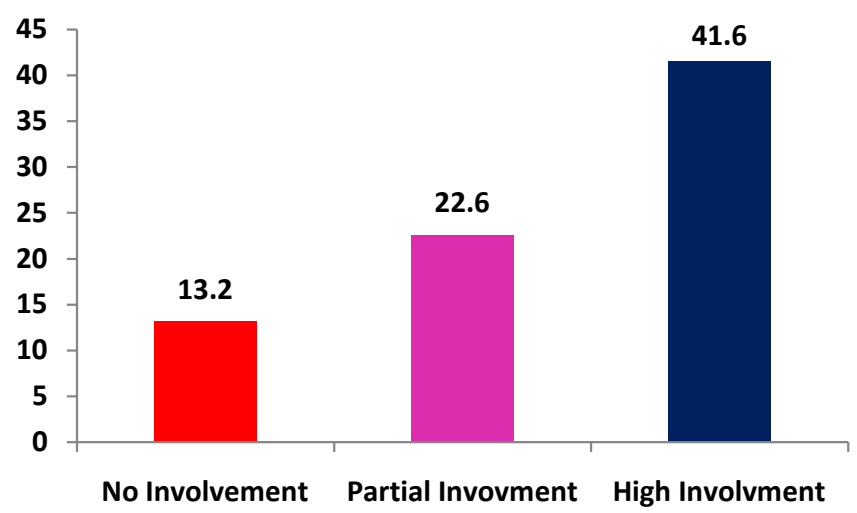

Figure 4. Percentage of currently married women who delivered in a health facility by male involvement, Uttar Pradesh, 2005-06.

\subsection{Male Involvement}

A number of interventions in India and Ethiopia have shown significant increases in family planning use when men participate in counseling with their wives (Population Council, 2004; Terefe, 1993) [26] [27]. Table 2 shows that after adjusting for other covariates mentioned above and women's autonomy, high male involvement is positively associated with getting full ante-natal care $(\mathrm{OR}=2.03, \mathrm{p}<0.05)$, institutional delivery $(\mathrm{OR}=1.87, \mathrm{p}<0.001)$, delivery assisted by health professional $(\mathrm{OR}=1.79, \mathrm{p}<0.01)$, post-natal care $(\mathrm{OR}=2.27, \mathrm{p}<0.001)$, and adoption of permanent family planning $(\mathrm{OR}=$ $1.79, \mathrm{p}<0.05)$. Adjusted odds ratio estimated from the logistic regression model shows women currently using modern family planning method is significantly associated with 
Table 2. Multivariate (adjusted) odds ratio estimated from logistic regression model of select $\mathrm{RCH}$ services by Woman's Autonomy and Male Involvement indices controlling for selected socio-economic and demographic variables, Uttar Pradesh, 2005-2006.

\begin{tabular}{|c|c|c|c|c|c|c|}
\hline \multirow[b]{2}{*}{ RCH Services } & \multicolumn{3}{|c|}{ Women's Autonomy } & \multicolumn{3}{|c|}{ Male Involvement } \\
\hline & $\begin{array}{c}\text { Low } \\
(\mathrm{n}=1247)\end{array}$ & $\begin{array}{l}\text { Medium } \\
(\mathrm{n}=1200)\end{array}$ & $\begin{array}{l}\text { High }^{\star *} \\
(\mathrm{n}=238)\end{array}$ & $\begin{array}{c}\text { No } \\
(\mathrm{n}=949)\end{array}$ & $\begin{array}{c}\text { Partial } \\
(\mathrm{n}=1440)\end{array}$ & $\begin{array}{l}\text { High }^{\star *} \\
(\mathrm{n}=296)\end{array}$ \\
\hline Women availed: Full ANC & 1 & 1.227 & $2.479^{\star *}$ & 1 & 1.522 & $2.025^{\star}$ \\
\hline Institutional delivery & 1 & 0.865 & 0.81 & 1 & $1.292^{*}$ & $1.869^{* * *}$ \\
\hline $\begin{array}{l}\text { Delivery assisted by health } \\
\text { professional }\end{array}$ & 1 & 0.858 & 0.782 & 1 & $1.298^{*}$ & $1.785^{\star *}$ \\
\hline Post-natal care & 1 & 1.008 & 1.387 & 1 & 1.244 & $2.269^{* * *}$ \\
\hline $\begin{array}{l}\text { Use of FP method: Any FP } \\
\text { method }\end{array}$ & 1 & 0.856 & 0.826 & 1 & 1.105 & 1.053 \\
\hline Modern method & 1 & 0.959 & 0.951 & 1 & 1.181 & $1.406^{*}$ \\
\hline Modern spacing method & 1 & 0.965 & 0.956 & 1 & 0.941 & 1.109 \\
\hline Permanent method & 1 & 0.934 & 0.958 & 1 & $1.557^{\star}$ & $1.790^{*}$ \\
\hline Child morbidities: Fever & 1 & $0.707^{\star *}$ & 0.723 & 1 & $0.774^{*}$ & $0.657^{\star}$ \\
\hline Diarrhea & 1 & 0.896 & 1.052 & 1 & 0.93 & 1.101 \\
\hline ARI & 1 & $0.763^{+}$ & $0.582^{+}$ & 1 & 0.891 & 0.789 \\
\hline Any Morbidity & 1 & $0.742^{\star *}$ & 0.814 & 1 & $0.794^{*}$ & 0.811 \\
\hline $\begin{array}{c}\text { Initiation of BF within one } \\
\text { hour }\end{array}$ & 1 & 1.148 & 1.007 & 1 & $1.578^{\star *}$ & $2.160^{* * *}$ \\
\hline Child immunization: BCG & 1 & 908 & 0.743 & 1 & 1.214 & 1.522 \\
\hline DPT3 & 1 & 1.085 & 0.912 & 1 & 1.111 & 1.335 \\
\hline Polio3 & 1 & 0.716 & 1.673 & 1 & 0.957 & 1.597 \\
\hline Measles & 1 & 1.143 & 0.962 & 1 & 1.235 & 1.37 \\
\hline Full immunization & 1 & 1.107 & 0.718 & 1 & 0.952 & 1.446 \\
\hline Stunting (Height-for-age) & 1 & 0.979 & 0.895 & 1 & 0.933 & $0.769^{+}$ \\
\hline Wasting (Weight-for-age) & 1 & 0.953 & $0.688^{*}$ & 1 & 0.889 & 0.773 \\
\hline $\begin{array}{c}\text { Under-nutrition } \\
\text { (Weight-for-height) }\end{array}$ & 1 & 0.88 & 0.956 & 1 & 0.88 & 0.825 \\
\hline $\begin{array}{l}\text { Availed ICDS services } \\
\text { during pregnancy }\end{array}$ & 1 & 0.949 & 0.962 & 1 & $1.930^{*}$ & $4.358^{* * *}$ \\
\hline
\end{tabular}

Source: Computed from NFHS III data file. Note: Odds ratios are adjusted for woman's age, place of residence, having currently living children, caste/tribe, woman's education status, woman's standard of living (wealth index), type of family, exposure to mass media, husband's age, education, and occupation. ${ }^{+}<0.1,{ }^{*} \mathrm{p}<0.05$; ${ }^{* *} \mathrm{p}<0.01$; ${ }^{* *} \mathrm{p}<$ $0.001 ; 1.00$ : reference category.

high male involvement $(\mathrm{OR}=1.41, \mathrm{p}<0.05)$.

The multivariate analysis further revealed that partial male involvement $(\mathrm{OR}=1.58$, $\mathrm{p}<0.01)$ and high male involvement $(\mathrm{OR}=2.16, \mathrm{p}<0.001)$ were positively associated with initiation of breastfeeding within one hour of birth. Women whose spouses are partially or highly involved in their health are one and a half to two times more likely to 
initiate breastfeeding within one hour of birth compared to women whose husbands were not involved. High male involvement is also strongly associated with utilization of Integrated Child Development Services (ICDS) in Uttar Pradesh $(\mathrm{OR}=4.36 . \mathrm{p}<0.001)$ and lower stunting of children $(\mathrm{OR}=0.77, \mathrm{p}<0.10)$. Women whose husbands are highly involved are four times more likely to utilize ICDS services compared to those with husbands who have not been involved.

\section{Discussion}

It is well established that in patriarchal societies like India, wives have low status in the family hierarchy. Their needs often come last (Sen 2004) [1]. For example, women in many parts of India, Uttar Pradesh, depend on other family members (husband and in-laws) in almost every domain of decision making, including the sphere of health care (Jejeebhoy et al., 1998) [28] In addition, low social and economic status of women can create barriers to women empowerment and often women's health needs are given least priority which may lead to poor reproductive health status (Koenig et al., 1998) [29]. She has to take permission for most decisions and depends on others' decision about financial matters in the household. (Mahajan, 1990) [30]. In most of the households in India, if a woman falls sick or has a complication in pregnancy, she must depend on her husband or in-laws for seeking treatment and for buying medicine (Martin et al. 1999) [31]. If women are not allowed to take decisions regarding their healthcare especially when men or head of the household are not around, it is nothing but denying her right to live a healthy life. Women should have the choice to and ability of taking decisions regarding their health care. Women empowerment should be seen as a basic human right. The ICPD recognized the significance of women empowerment and reiterated that reproductive health is an indispensable part of women's empowerment.

From the above analysis, it is quite evident that although women's autonomy improves the utilization of $\mathrm{RCH}$ services, male involvement appears to be a key factor for overall utilization of RCH and Integrated Child Development Services (ICDS). It appears that when health workers provide maternal and child health information to husbands, there is a strong association with positive health outcomes and service utilization. It is therefore important for maternal and child health service delivery programs to reach out to husbands/fathers with behavior change communication efforts and encourage men to be involved in their spouses' and children's health care to bring about improvements in the health and nutritional status of women and children. Similarly, communication interventions should encourage joint decision making between the spouses around health care issues. While factors such as woman's age, place of residence, caste, tribe, women's education status, women's standard of living (wealth index), type of family and exposure to mass media play an important role in determining differential utilization of $\mathrm{RCH}$ services, these are not easily modified. A behavior change strategy to encourage male involvement through joint husband-wife decisionmaking, encouraging men to be present during visits to health facilities, and targeting men for information on maternal and child health will enhance the utilization of $\mathrm{RCH}$ 
services, thereby improving their health status.

\section{Limitations}

This study made every effort to rigorously explore the effects of women's autonomous decision-making power as well as male involvement on utilization of RCH services. However, there are limitations of such secondary data analyses. The analysis was restricted to women who gave birth in the three years preceding the NFHS-3 (2005-06) survey. As the National Family Health Survey was not designed to focus on either women's autonomous decision-making or male involvement, there were only a few questions related to these issues. Those specific questions from the survey were included to construct indices for women's autonomy and male involvement, which may not cover all elements of these constructs, given their multidimensionality. Further, this study points to the need for a greater understanding of the relationship between male involvement and utilization of RCH services and maternal and child health outcomes. This can be achieved through expanding questions on male involvement in the next DHS/NFHS and through further operational research.

\section{Conclusion}

The findings clearly indicate that, in Uttar Pradesh, those women having support of their husband (male involvement) are significantly more likely to utilize of RCH services for themselves and their children. These women are more likely to utilize full antenatal care during pregnancy, deliver in health institutions, be assisted during delivery by a health professional, use permanent family planning, and avail ICDS services, and be less likely to have children suffering from fever or malnutrition (stunting and wasting). The findings of this study make a strong argument for ensuring the involvement of men in RCH Programming. This would include special efforts appropriate to men that would provide information about maternal and child health as well as encourage men's presence during maternal and child health service delivery.

\section{Acknowledgements}

This study was made possible by the support of the American People through the United States Agency for International Development (USAID). USAID's MCH-STAR Initiative worked in collaboration with the PFI to conduct this study. USAID/India's MCH-STAR initiative aims to create a legacy of Indian institutions, like PFI, that provide technical leadership in research, program evaluation, policy analysis, responsive technical assistance and advocacy of global standards in maternal, neonatal, child health and nutrition. The contents of this paper are the sole responsibility of the authors and do not necessarily reflect the views of USAID or the United States Government.

\section{References}

[1] Sen, G., Germain, A. and Chen, L.C. (1994) Population Policies Reconsidered: Empower- 
ment and Rights. Harvard University Press, Harvard Series on Population and International Health, Massachusetts, 653.

[2] Cohen, S.A. and Richards, C.L. (1994) The Cairo Consensus: Population, Development and Women. Family Planning Perspectives, 26, 272-277. https://doi.org/10.2307/2135895

[3] UNFPA (2004) Investing in People: National Progress in Implementing the ICPD Program of Action 1994-2004. Special Report.

[4] Ronsmans, C. and Graham, W.J., Lancet Maternal Survival Series Steering Group (2006) Maternal Mortality: Who, When, Where, and Why. The Lancet, 368, 1189-1200.

[5] World Health Organization (2005) The World Health Report 2005: Make Every Mother and Child Count. WHO, Geneva.

[6] World Health Organization (2004) Maternal Mortality in 2000: Estimates Developed by WHO, UNICEF and UNFPA. World Health Organization.

[7] United Nations (2006) The Millenium Development Goals Report 2006. New York.

[8] Cham, M., Sundby, J. and Vangen, S. (2005) Maternal Mortality in the Rural Gambia, a Qualitative Study on Access to Emergency Obstetric Care. Reproductive Health, 2, 3. https://doi.org/10.1186/1742-4755-2-3

[9] Furuta, M. and Salway, S. (2006) Women's Position within the Household as a Determinant of Maternal Health Care Use in Nepal. International Family Planning Perspectives, 32, 17 27. https://doi.org/10.1363/3201706

[10] Dutta, T. and Mondal, S. (2010) Analyzing Women's Reproductive Health Outcomes through a Rights' Perspective-The Indian Scenario. Conference Poster, Asian Population Association. Delhi.

[11] Caldwell, J. and Caldwell, P. (1993) Women's Position and Child Mortality and Morbidity in Less Developed Countries. In: Mason, K., Federici, N. and Sogner, S., Eds., Women's Position and Demographic Change, Clarendon Press, Oxford, 122-139.

[12] Dyson, T. and Moore, M. (1983) On Kinship Structure, Female Autonomy, and Demographic Behaviour in India. Population and Development Review, 9, 35-60. https://doi.org/10.2307/1972894

[13] Jejeebhoy, S. and Sathar, Z. (2001) Women's Autonomy in India and Pakistan: The Influence of Religion and Region. Population and Development Review, 27, 687-712. https://doi.org/10.1111/j.1728-4457.2001.00687.x

[14] Ghuman, S.J. (2003) Women's Autonomy and Child Survival: A Comparison of Muslims and Non-Muslims in Four Asian Countries. Demography, 40, 419-436. https://doi.org/10.1353/dem.2003.0021

[15] Mason, K.O. (1987) The Impact of Women's Social Position on Fertility in Developing Countries. Sociological Forum, 2, 718-745. https://doi.org/10.1007/BF01124382

[16] Miles-Doan, R. and Bisharat, L. (1990) Female Autonomy and Child Nutritional Status: The Extended Family Residential Unit in Amman, Jordan. Social Science \& Medicine, 31, 783-789. https://doi.org/10.1016/0277-9536(90)90173-P

[17] Moursund, A. and Kravdal, Ø. (2003) Individual and Community Effects of Women's Education and Autonomy on Contraception Use in India. Population Studies, 57, 285-301. https://doi.org/10.1080/0032472032000137817

[18] Dharmalingam, A. and Morgan, S.P. (1996) Women's Work, Autonomy, and Child Birth Control: Evidence from two South Indian villages. Population Studies, 50, 187-201. https://doi.org/10.1080/0032472031000149296

[19] Sunil, T.S., Rajaram, S. and Zottarelli, L.K. (2006) Do Individual and Program Factors Mat- 
ter in the Utilization of Maternal Care Services in Rural India? A Theoretical Approach. Social Science and Medicine, 62, 1943-1957. https://doi.org/10.1016/j.socscimed.2005.09.004

[20] Ministry of Health and Family Welfare (MoHFW) (2000) National Population Policy 2000. Government of India, New Delhi.

[21] Planning Commission (2002) Planning Commission Tenth Five Year Plan (2002-2007). Vol. 2, Sectoral Policies and Programs, Family Welfare, Government of India, New Delhi.

[22] Khan, M.E. and Panda. P (2004) Involving men in Reproductive Health in India: Policies, Programs and Achievements. The Journal of Family Welfare, 50, 50-57.

[23] Government of Uttar Pradesh Uttar Pradesh Population Policy (2000) Department of Health and Family Welfare. Government of Uttar Pradesh.

[24] International Institute for Population Sciences and Macro International. National Family Health Survey III, 2005-06. IIPS, Mumbai.

[25] International Institute for Population Sciences (2007) National Family Health Survey (NFHS-3), 2005-06: India. Mumbai, India: International Institute for Population Sciences.

[26] Terefe, A. and Larson, C.P. (1993) Modern Contraception Use in Ethiopia: Does Involving Husbands Make a Difference? American Journal of Public Health, 83, 1567-1571.

[27] Population Council Report of the Frontier Project in India (2004).

[28] Jejeebhoy, S.J. (1998) Adolescent Sexual and Reproductive Behavior: A Review of the Evidence from India. Social Science \& Medicine, 46, 1275-1290. https://doi.org/10.1016/S0277-9536(97)10056-9

[29] Koenig, M., Jejeebhoy, S., Singh, S. and Sridhar, S. (1998) Investigating Women's s Gynaecological Morbidity in India: Not Just another KAP Survey. Reproductive Health Matters, 6, 84-97. https://doi.org/10.1016/S0968-8080(98)90085-4

[30] Mahajan, A. (1990) Instigators of Wife Battering. In: Sood, S., Ed., Violence against Women, Arihant Publishers, Jaipur, 1-10.

[31] Martin, S.L., Kilgallen, B., Tsui, A.O., Maitra, K., Singh, K.K. and Kupper, L.L. (1999) Sexual Behaviors and Reproductive Health Outcomes: Associations with Wife Abuse in India. JAMA, 282, 1967-1972. https://doi.org/10.1001/jama.282.20.1967

\section{Submit or recommend next manuscript to SCIRP and we will provide best service for you:}

Accepting pre-submission inquiries through Email, Facebook, LinkedIn, Twitter, etc. A wide selection of journals (inclusive of 9 subjects, more than 200 journals)

Providing 24-hour high-quality service

User-friendly online submission system

Fair and swift peer-review system

Efficient typesetting and proofreading procedure

Display of the result of downloads and visits, as well as the number of cited articles Maximum dissemination of your research work

Submit your manuscript at: http://papersubmission.scirp.org/

Or contact ojpm@scirp.org 